Veeravel, V., \& Mohanasundaram, S. (2020). Market Timing Abilities of Large Cap Equity Mutual Fund Managers: Evidence from India. Copernican Journal of Finance \& Accounting, 9(4), 87-99. http://dx.doi.org/10.12775/CJFA.2020.023

\author{
V. Veeravel* \\ Pondicherry University \\ S. Mohanasundaram ${ }^{* *}$ \\ Pondicherry University
}

\title{
MARKET TIMING ABILITIES OF LARGE-CAP EQUITY MUTUAL FUND MANAGERS: EVIDENCE FROM INDIA
}

Keywords: large-cap funds, conditional models, public information variables, market timing abilities.

J E L Classification: C12, G11, G23.

Abstract: This study investigates the Market Timing Ability (MTA) of large-cap equity fund managers in India. The extensions of Treynor and Mazuy (TM) model and Henriksson and Merton (HM) model have been used by adding six additional factors related to the public information, 91-days Treasury bill's yield, the dividend yield on CNX 500 index, term structure of interest rates, the price-to-earnings ratio, yield from foreign exchange rates changes, and growth rate in gold prices. The extended models are termed, conditional models. This study has used time-series data of large-cap equity funds. The results of the conditional and unconditional versions of TM and HM models reveal that the large-cap equity funds as a whole do not possess significant MTA, even

Date of submission: December 10, 2020; date of acceptance: March 3, 2021.

* Contact information: veeravel91@gmail.com, Research Scholar, Department of Banking Technology, School of Management, Pondicherry University, Puducherry 605014, India, phone: +91 74183 46733; ORCID ID: https://orcid.org/0000-0003-1597-1777.

** Contact information: s.mohanasundaram@outlook.com, Research Scholar, Department of Management Studies, School of Management, Pondicherry University, Puducherry 605014, India, phone: +91 99414 59900; ORCID ID: https://orcid.org/00000003-4639-9419. 
though a considerable percentage of the funds under each of the models show significant positive MTA. The study also highlights that the inclusion of the public information variables reconstitutes the impact of the market timing factor and other beta estimates in the model.

\section{IIIINTRODUCTION}

The mutual fund industry in India has attained substantial progress in the past two decades. According to AMFI (2020), "the assets under management of Indian mutual fund industry have grown from Rs. 26.94 trillion in November 2019 to Rs. 29.83 trillion in November 2020". The fund managers in India are active in wealth maximisation, diversification of portfolio risk, and effective and efficient selection of portfolios. With the rapid growth of the industry, the investors seek the answers concerning the Market Timing Ability (MTA) of fund managers. Many methods have been used in the literature to measure the MTA. Among those, the model proposed by Treynor and Mazuy (1966) and the model proposed by Henriksson and Merton (1981) are commonly used. The study employs these two methods with public information variables, an improvement with the traditional measures (Becker, Ferson, Myers \& Schill, 1999; N. P. B. Bollen \& Busse, 2001; Bollen \& Pool, 2008; Deb, 2019; Dhar \& Mandal, 2014; Elton, Gruber \& Blake, 2012; Ferson \& Warther, 1996; Sehgal \& Babbar, 2017; Sehgal \& Jhanwar, 2008). The conditional version applied with public information variables assumes semi-strong market efficiency.

The present research paper consists of six sections. Section 2 surveys the existing academic literature on MTA. Section 3 gives a brief information on the data under this study and their sources. Section 4 summarises the research methodology. The empirical results are discussed in section 5 . The findings and the concluding remarks are presented in section 6 .

\section{REVIEW OF LITERATURE}

In the early 1990s, the researches on mutual funds extended to study the performance evaluation, persistence of performance, stock-picking skills (SPS) and market timing abilities (MTA). Although most of the studies were based on the CAPM with multifactor portfolio benchmarks, a few studies (Jensen, 1968; Sharpe, 1966; Treynor, 1965) failed to report superior fund performance. Grinblatt and Titman (1989) propose multiple benchmark portfolios based on the 
firms' characteristics such as size, past returns, and dividend yield. The models with the empirical explanation of the returns of the assets (Fama \& French, 1993; Ippolito, 1986) are also proposed. Carhart (1997) studied the impact of the momentum factor along with three-factors studied by Fama and French (1993). The multi-factor are found to be explaining the performance of the funds are better than a single factor model.

To assess the MTA, Treynor and Mazuy (1966) proposed a model (hereafter, TM model). Having this model as a base, Henriksson and Merton (1981) proposed a model (hereafter, HM model), with the replacement of quadratic term by a dummy variable with maximum 1 and minimum 0 . A parametric statistical test by Kon and Jen (1979) and Chang and Lewellen (1984) finds no MTA of passive investment managers. A number of extensions on TM models are also developed (Fletcher, 1995; Jagannathan \& Korajczyk, 1986; Lee \& Rahman, 1990).

Becker et al. (1999) suggests that the model specification could be improved by conditioning on the variables of public information, and no significant evidence for MTA, after controlling for the public information. However, daily data is found to be better than monthly data in terms of significant MTA (Bollen \& Busse, 2001). The nonparametric test on large-cap mutual funds from 1980-1999 with different benchmark indices by Jiang (2003) does not find any significant MTA. Christensen (2005) studies the SPS and MTA in Danish market by applying single index, multifactor model, quadradic regression approach of TM Model, and options approach of HM Model and finds no significant evidence for MTA.

Chen and Liang (2007) examine the hedge funds by applying timing return and volatility together, relating the returns to the Sharpe ratio and find significant MTA in a bear market and volatile market conditions. Elton et al. (2012) applied a single index model to study the MTA with monthly holdings. They find that the managers appear to show a significant positive MTA. The study using FDR with the inclusion of MTA variables by Cuthbertson and Nitzsche (2013) in German market reveals the positive alpha performance of funds.

In Indian context, the results of the studies using the unconditional and conditional models (Deb, Banerjee \& Chakrabarti, 2007; Dhar \& Mandal, 2014; Sehgal \& Jhanwar, 2008; Tripathy, 2005, 2006) find no evidence for MTA and SPS. However, Chopra (2011) documents mixed results for MTA. Sehgal and Babbar (2017) proposes the alternative performance benchmarks for evaluating the funds. The application of the constrained quadratic factor model by Mohanti and Priyan (2018) reveals a significant level of active management and superi- 
or SPS. Bandi and Gupta (2019) find that only three fund managers display superior SPS, and only two funds show MTA during the study period. The studies on Indian mutual funds market have focused more on the performance of equity funds, specifically Jensen's (1968) alpha. Even though a number of studies have been conducted on large-cap equity mutual funds so far, there is no study which considers of the public information variables to examine the MTA and hence, this study attempts to bridge this gap.

\section{DATA}

The scope of this study is the Indian large-cap equity mutual funds that are growth-oriented. As of March, 2020, there are 206 active funds under this category. The funds having data for more than 36 months are retained for the study and 35 funds which are not meeting this criterion have been eliminated. Thus, the sample size of this study is 171 . This study covers the period from January, 2000 to December, 2019. The Bloomberg database has been used to collect the data for the study. The Net Assets Value (NAV) has been used to calculate funds' returns. The S\&P BSE 200 index has been used as the market proxy. The 91-days Treasury bills return, collected from the website of $\mathrm{RBI}^{1}$, is used as a proxy for the risk-free assets.

\section{PUBliC INFORMATION VARIABLES}

The selected Public Information Variables (PIV) suggested by Ferson and Schadt (1996) have been used for controlling or forecasting the stock returns and risk over a period of time. For conditioning the alpha and beta values, the six important macroeconomic variables namely, 91-days treasury bills yield (TB), the dividend yield on CNX 500 index (DY), the term structure of interest rates (TS), the aggregate $\mathrm{P} / \mathrm{E}$ ratio (PE), yield from USD exchange rates changes (FX), and growth rate in gold prices (GP). Bloomberg database has been used to collect the data for these variables.

${ }^{1}$ RBI (Reserve Bank of India): National Summary Data Page https://www.rbi.org. in/Scripts/BS_NSDPDisplay.aspx?param $=4$ 


\section{METHODOLOGY}

We apply the unconditional TM and HM models and the conditional TM and HM models to measure the MTA of large-cap equity funds. In order to find significant MTA, we use monthly mutual fund returns calculated from net assets values of each fund as

$$
R_{t}=\frac{N A V_{t}-N A V_{t-1}}{N A V_{t-1}}
$$

where, $R_{t}$ is the return of the fund at time $t, N A V_{t}$ is the net assets value of the fund for at time $t$, and $N A V_{t-1}$ is the net assets value at time $t-1$. The market return computed as

$$
\mathrm{R}_{m, t}=\frac{\mathrm{P}_{t}-\mathrm{P}_{t-1}}{\mathrm{P}_{t-1}}
$$

where, $R_{m, t}$ is the return of the market portfolio at time t, $P_{t}$ is the closing price of market portfolio at time $t, P_{t-1}$, is the closing price of the index at $t-1$. The yield on 91-day T-bills return is calculated on monthly basis.

\section{UnConditional Models of MARKet Timing Ability}

The literature shows that there is a difference between the performance of the funds with respect to stock-selection and timing ability. Different risk models are used to verify whether SPS and MTA can be predicted. It is understood that the single factor model measures the SPS. However, the change in strategies by the managers in the portfolio construction is not accounted. A quadratic term has been added to the single factor model to capture the convexity of the fund returns and market returns. The TM model is represented as

$$
R_{p}-R_{f}=\alpha+\beta\left(R_{m}-R_{f}\right)+\gamma\left(R_{m}-R_{f}\right)^{2}+\varepsilon_{p}
$$

where $R_{p}$ is the return of fund $p ; R_{m}$ is the return on the market index; $R_{f}$ is the risk-free rate; $\alpha$ Jensen's alpha; $\beta$ is systematic risk of fund $p$; $\varepsilon_{p}$; is the error term; $\gamma$ is estimate of the timing ability of the fund $p$. If significant positive $\gamma$, 
denotes the result of convex to the portfolio with respect to the market and the fund is considered to possess the MTA.

The HM model regresses using a dummy variable as the independent variable. A fund with higher beta value implies that the market does outperform, while fund-beta with lower value implies that the market exhibits poor performance. Hence, in line with risk-return theories, fund managers tend to choose high beta funds when they expect higher market returns. The equation of the HM model is represented by the equation

$$
R_{p}-R_{f}=\alpha+\beta\left(R_{m}-R_{f}\right)+\gamma D\left(R_{m}-R_{f}\right)+\varepsilon_{p}
$$

where $R_{p}, R_{m}, R_{f}, \alpha, \beta$ and $\varepsilon_{p}$ are citrus paribus as (3), $D$ refers to dummy variable with the value 1 with positive excess markets return and 0 with negative market return. The estimate $\gamma$ measures the difference between the bull and bear market $\beta \mathrm{s}$. A positive/negative significant $\gamma$ refers to that the fund manager is a successful/unsuccessful macro predictor and market timer.

\section{Conditional Models of MaRKet Timing Ability}

The conditional MTA model (Ferson \& Warther, 1996) is built on the understanding that the Jensen's alpha possesses the information of Public Information Variables (PIVs). This model assesses the ability of the managers to capitalise the publicly available information. This is because of the assumption that educated investors who have similar kind of information, can react consequently, to get the advantages out of the available information. The conditional timing ability model assumes that investment managers may modify their strategies over a period based on the information accessible to the public. This study uses six forecasting PIVs, which are well documented in the existing literature, for calculating conditioning alphas and betas. These PIVs are proven to be significant in many studies (e.g. Pesaran \& Timmermann, 1995).

$$
\begin{aligned}
R_{p}-R_{f}=\alpha & +\beta_{0}\left(R_{m}-R_{f}\right) T B_{t-1}+\beta_{2}\left(R_{m}-R_{f}\right) D Y_{t-1}+\beta_{3}\left(R_{m}-R_{f}\right) T S_{t-1} \\
& +\beta_{4}\left(R_{m}-R_{f}\right) P E_{t-1}+\beta_{5}\left(R_{m}-R_{f}\right) F X_{t-1}+\beta_{6}\left(R_{m}-R_{f}\right) G P_{t-1} \\
& +\gamma\left(R_{m}-R_{f}\right)^{2}+\varepsilon_{p}
\end{aligned}
$$




$$
\begin{aligned}
R_{p}-R_{f}=\alpha & +\beta_{0}\left(R_{m}-R_{f}\right)+\beta_{1}\left(R_{m}-R_{f}\right) T B_{t-1}+\beta_{2}\left(R_{m}-R_{f}\right) D Y_{t-1} \\
& +\beta_{3}\left(R_{m}-R_{f}\right) T S_{t-1}+\beta_{4}\left(R_{m}-R_{f}\right) P E_{t-1}+\beta_{5}\left(R_{m}-R_{f}\right) F X_{t-1} \\
& +\beta_{6}\left(R_{m}-R_{f}\right) G P_{t-1}+\gamma D\left(R_{m}-R_{f}\right)+\varepsilon_{p}
\end{aligned}
$$

The conditional TM model and the conditional HM model are represented by (5) and (6) respectively, where, $R_{p}, R_{m}, R_{f}, \alpha, \beta$ and $\varepsilon_{p}$ are citrus paribus as (3), $T B_{t-1}$ refers yield on 91-day treasury bill rates; $D Y_{t-1}$ is the dividend yield on CNX 500 market index; $T S_{t-1}$ denotes term structure rates; $P E_{t-1}$ indicates price-toearnings ratio; and $F X_{t-1}$ refers yield on foreign exchange rates.

\section{EMPIRICAL RESULTS}

Table 1 exhibits the summary of funds with positive and negative $\gamma$ estimate as per the unconditional and conditional models.

Table 1. Funds with Positive and Negative $\gamma$

\begin{tabular}{|l|c|c|c|c|c|c|}
\hline \hline & \multicolumn{2}{|c|}{ Number of Funds } & \multicolumn{2}{c|}{ Significant } & \multicolumn{2}{c|}{ Insignificant } \\
\hline \hline & Positives & Negatives & Positives & Negatives & Positives & Negatives \\
\hline \hline Treynor \& Mazuy & 131 & 40 & 79 & 3 & 52 & 37 \\
\hline Unconditional Model & 118 & 53 & 67 & 3 & 51 & 50 \\
\hline Conditional Model & & & & & & 58 \\
\hline Henriksson \& Merton & 133 & 38 & 75 & 3 & 35 & 48 \\
\hline Unconditional Model & 120 & 51 & 65 & 3 & 55 & 35 \\
\hline Conditional Model & & & & & & \\
\hline \hline
\end{tabular}

S o u r c e : authors' calculations.

The unconditional TM model reveals that out of 171 funds, 79 funds show significant ( $p=0.05$ ) positive $\gamma$ estimate, which means that there is 46 per cent of fund managers outperform the market with significant market timing ability. Only three funds exhibit negative significant negative estimate for MTA factor. 
The conditional TM model reveals that 67 funds show significant $(\mathrm{p}=0.05)$ positive $\gamma$ estimate, which means that there is 39 per cent of fund managers outperform the market with significant market timing ability. Only three funds exhibit significant negative $\gamma$ estimate. Further, the interesting finding is that the fund showing a significant positive $\gamma$ estimate in unconditional TM model are not the same funds which show a significant positive $\gamma$ estimate in the conditional TM model, which means that the inclusion of the PIVs reconstitutes the estimates, while the coefficient of determination of the model is being improved.

The results of the unconditional HM model exhibit that 75 funds show a significant positive $\gamma$ estimate, which means that there is 44 per cent of fund managers outperform the market with significant $(p=0.05)$ market timing ability and only three funds exhibit significant negative $\gamma$ estimate. The results of the conditional HM model exhibit that 65 funds show significant positive $\gamma$ estimate, which means that there is 38 per cent of fund managers outperform the market with significant market timing ability and only three funds exhibit significant negative $\gamma$ estimate. Similar to HM model, the fund showing the significant positive $\gamma$ estimate in unconditional TM model are not the same funds which show significant positive $\gamma$ estimate in the conditional TM model.

Table 2 shows the summary of the $\gamma$ estimate of the funds as per the four models, after removing the outliers.

Table 2. Summary of $\gamma$ Estimate from Unconditional and Conditional Models

\begin{tabular}{|l|c|c|c|c|c|c|}
\hline \hline & Mean & S.D. & Median & Min. & Max. & S.E. \\
\hline \hline \multicolumn{7}{|l|}{ Treynor \& Mazuy } \\
\hline Unconditional Model & 0.3782 & 0.4652 & 0.3867 & -0.8338 & 1.3859 & 0.0411 \\
\hline Conditional Model & 0.5133 & 0.8335 & 0.5899 & -1.8898 & 2.4125 & 0.0737 \\
\hline Henriksson \& Merton & 0.1109 & 0.1120 & 0.1311 & -0.2329 & 0.4319 & 0.0099 \\
\hline Unconditional Model & 0.4915 & 0.8103 & 0.5657 & -1.8791 & 2.4140 & 0.0716 \\
\hline Conditional Model &
\end{tabular}

S o u r c e : authors' calculations. 
It is evident that the inclusion of the mean $\gamma$ estimate is increasing with the addition of the PIVs. However, the standard deviation of $\gamma$ estimate is also increasing, which results in high standard error. It is also notable that even though the mean $\gamma$ estimate is positive in all the models, the number of funds having significant positive $\gamma$ estimate is not significantly above 50 percent of the sample. The positive mean $\gamma$ estimate is because of the high magnitude the estimate of the funds with positive estimate than that of the funds with negative estimate.

The bootstrap technique helps to find the unbiased $\gamma$ estimate and to find the confidence interval for it. The Bias Corrected Accelerated ( $\left.\mathrm{BC}_{\mathrm{a}}\right)$ interval provides the accurate coverage after correcting the bias and skewness in bootstrap distribution, if any. Table 3 exhibits the summary of the bootstrap with 1000 bootstrap samples.

Table 3. Bootstrap Summary of $\gamma$ Estimate

\begin{tabular}{|l|c|c|c|c|}
\hline \hline & Bootstrap Estimate & Bias & S.E. & BCa Interval \\
\hline \hline \multicolumn{5}{|l|}{ Treynor \& Mazuy } \\
\hline Unconditional Model & 0.3792 & 0.00104 & 0.0410 & $(0.3034,0.4623)$ \\
\hline Conditional Model & 0.5135 & 0.00020 & 0.0734 & $(0.3708,0.6568)$ \\
\hline Henriksson \& Merton & 0.1112 & 0.00028 & 0.0098 & $(0.0914,0.1285)$ \\
\hline Unconditional Model & 0.4916 & 0.00006 & 0.0708 & $(0.3530,0.6240)$ \\
\hline Conditional Model &
\end{tabular}

S o u r c e : authors' calculations.

The bootstrap $\gamma$ estimates for all the four models are almost the same as the original $\gamma$ estimates in a meaning that the bias is very less. In both TM and HM models, the $\mathrm{BC}_{\mathrm{a}}$ interval as per the unconditional model is narrow, while the interval as per the conditional model is broad. This makes clear that the inclusion of the PIVs reconstitutes the impact of the factors in the models thereby impacting their corresponding estimates. The distributions of the $\gamma$ estimate of the bootstrap samples $(B=1000)$ as per all the four models have been represented in Figure 1. 
Figure 1. Bootstrap Distributions of $\gamma$ Estimate
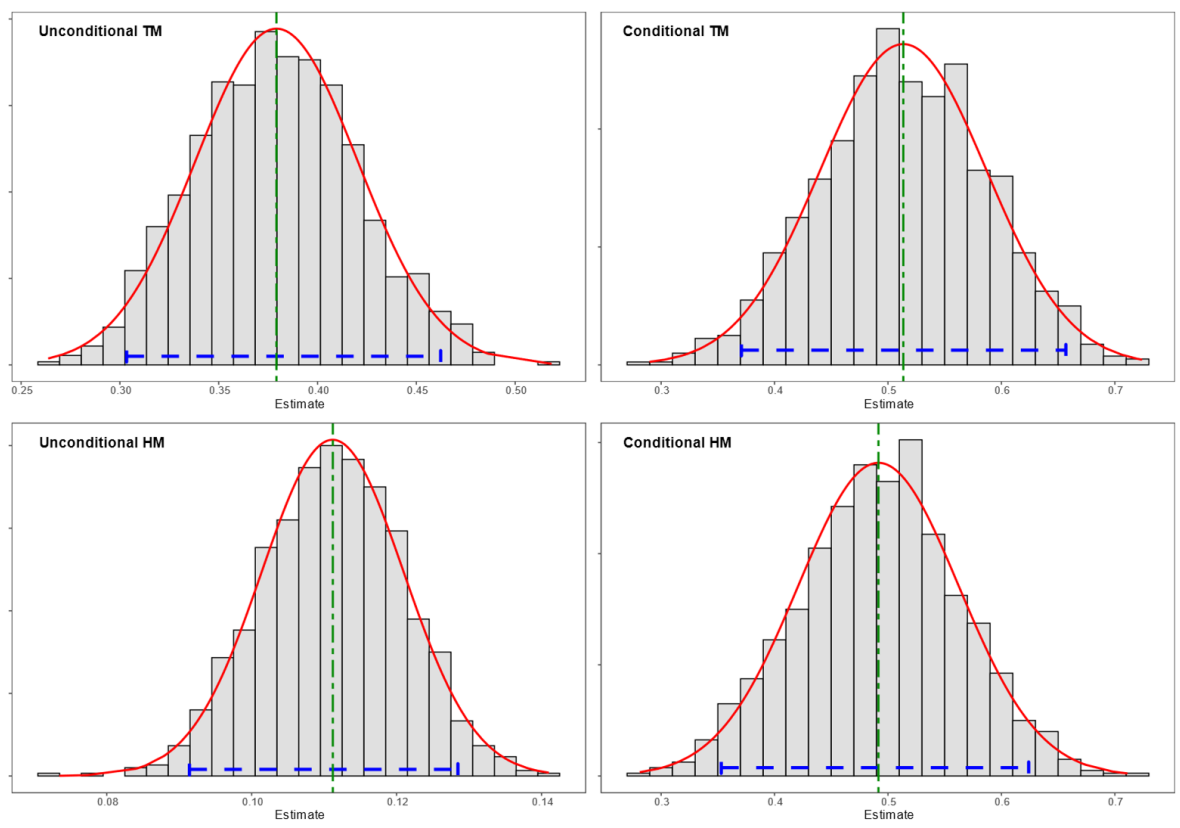

- Normal Density - - BCa Interval - - Bootstrap Estimate

S o u r c e : created by authors using R.

\section{ConCLUSION}

The objective of this paper is to investigate the Market Timing Ability (MTA) of large-cap equity funds from January, 2000 to December, 2019. This study applies TM and HM models and their extensions termed conditional TM and HM models with the inclusion of public information variables (PIVs).

The results find that a smaller number of fund managers have significant MTA for the whole study period. Around 46 percent of fund managers as per the unconditional TM model and 39 percent of the managers as per the unconditional HM model show significant MTA. These findings are in line with Chang and Lewellen (1984), Dhar and Mandal (2014), Goetzmann, Ingersoll Jr and Ivkovic (2000), Henriksson and Merton (1981), Sehgal and Jhanwar (2008), Treynor and Mazuy (1966) and Tripathy (2006). The results of the conditional versions of TM and HM models shows that 44 percent and 38 percent of the fund 
managers respectively show superior MTA. The evidence for timing ability is meagre. This finding is consistent with earlier studies, Becker et al. (1999), Dhar and Mandal (2014) and Elton et al. (2012). The inclusion of PIVs helps to strengthen the estimation of MTA. Hence, it can be concluded that the bias from the unconditional version is eliminated by controlling for the public information and this confirms the findings of previous studies (Becker et al., 1999; Deb et al., 2007; Dhar \& Mandal, 2014; Ferson \& Warther, 1996). Further, there is no significant evidence found in this study to support the hypothesis that largecap equity fund managers in India show different MTA at different time variations even after controlling for the effect of PIVs. The MTA models may support only for a short-term, and the persistent and precise forecast over the longterm is challenging. Therefore, the average investors can diversify their mutual fund portfolios in the long-term. This could be the best strategy for mutual fund managers. The empirical evidence out of this study on MTA of the largecap equity mutual funds in India contributes to the academic literature. There is a wide scope for carrying out a similar study with other types of funds.

\section{REFERENCES}

AMFI (2020). Association of Mutual Funds in India: Industry Trends, https://www.amfiindia.com/Themes/Theme1/downloads/home/industry-trends.pdf.

Bandi, S., \& Gupta, P. (2019). Performance of Mutual Funds in Indian Context Evaluation Market Timing Ability and Stock Selection Skills of the Fund Manager. Delhi Business Review, 20(2), 67-78. http://dx.doi.org/10.51768/dbr.v20i2.202201907.

Becker, C., Ferson, W., Myers, D.H., \& Schill, M.J. (1999). Conditional market timing with benchmark investors. Journal of Financial Economics, 52(1), 119-148. http://dx.doi. org/10.1016/s0304-405x(99)00006-9.

Bollen, N.P.B., \& Busse, J.A. (2001). On the Timing Ability of Mutual Fund Managers. The Journal of Finance Finance, 56(3), 1075-1094. http://dx.doi.org/10.1111/j.17456622.2008.00191.x.

Bollen, N., \& Pool, V.K. (2008). Conditional Return Smoothing in the Hedge Fund Industry. The Journal of Financial and Quantitative Analysis, 43(2), 267-298. http://dx.doi. org/10.1017/S0022109000003525.

Carhart, M.M. (1997). On Persistence in Mutual Fund Performance. The Journal of Finance, LII(1), 57-82. http://dx.doi.org/10.1111/j.1540-6261.1997.tb03808.x.

Chang, E.C., \& Lewellen, W.G. (1984). Market Timing and Mutual Fund Investment Performance. The Journal of Business, 57(1), 57-72. http://dx.doi.org/10.1086/296224.

Chen, Y., \& Liang, B. (2007). Do market timing hedge funds time the market? Journal of Financial and Quantitative Analysis, 42(4), 827-856. http://dx.doi.org/10.1017/ s0022109000003410. 
Chopra, M.P. (2011). Do Indian Mutual Fund Managers select the Stock and Time the Market Correctly? IUP Journal of Applied Finance, 17(2), 78-88.

Christensen, M. (2005). Danish Mutual Fund Performance-Selectivity, Market Timing and Persistence. Finance Research Group. Research Group Working Paper, F-2005-1. http://dx.doi.org/10.2139/ssrn.670701.

Cuthbertson, K., \& Nitzsche, D. (2013). Performance, stock selection and market timing of the German equity mutual fund industry. Journal of Empirical Finance, 21(1), 86101. http://dx.doi.org/10.1016/j.jempfin.2012.12.002.

Deb, S.G. (2019). Persistence in performance of actively managed equity mutual funds: New Indian evidence. IIMB Management Review, 31(2), 145-156. http://dx.doi. org/10.1016/j.iimb.2019.03.014.

Deb, S.G., Banerjee, A., \& Chakrabarti, B.B. (2007). Market timing and stock selection ability of mutual funds in India: An empirical investigation. Vikalpa, 32(2), 39-51. http://dx.doi.org/10.1177/0256090920070204.

Dhar, J., \& Mandal, K. (2014). Market timing abilities of Indian mutual fund managers: An empirical analysis. Decision, 41(3), 299-311. http://dx.doi.org/10.1007/s40622014-0036-2.

Elton, E.J., Gruber, M.J., \& Blake, C.R. (2012). An examination of mutual fund timing ability using monthly holdings data. Review of Finance, 16(3), 619-645. http://dx.doi. org/10.1093/rof/rfr007.

Fama, F., \& French, R. (1993). Common risk factors in the returns on stocks and bonds. Journal of Financial Economics, 33(1), 3-56. http://dx.doi.org/10.1016/0304405X(93)90023-5.

Ferson, W.E., \& Schadt, R.W. (1996). Measuring Fund Strategy and Performance in Changing Economic Conditions. The Journal of Finance, 51(2), 425-461.

Ferson, W.E., \& Warther, V.A. (1996). Evaluating fund performance in a dynamic market. Financial Analysts Journal, 52(6), 20-28. http://dx.doi.org/10.2469/faj.v52.n6.2037.

Fletcher, J. (1995). An Examination of the Selectivity and Market Timing Performance of UK Unit Trusts. Journal of Business Finance \& Accounting, 22(1), 143-156. http:// dx.doi.org/10.1111/j.1468-5957.1995.tb00676.x.

Goetzmann, W.N., Ingersoll Jr, J.E., \& Ivkovic, Z. (2000). Monthly Measurement of Daily Timers. The Journal of Financial and Quantitative Analysis, 35(3), 257-290. http:// dx.doi.org/10.2307/2676204.

Grinblatt, M., \& Titman, S. (1989). Mutual Fund Performance: An Analysis of Quarterly Portfolio Holdings. The Journal of Business, 62(3), 393-416. http://dx.doi. org/10.1086/296468.

Henriksson, R.D., \& Merton, R.C. (1981). On Market Timing and Investment Performance. II. Statistical Procedures for Evaluating Forecasting Skills. The Journal of Business, 54(4), 513-533. http://dx.doi.org/10.1086/296144.

Ippolito, R.A. (1986). Efficiency with Costly Information: A Study of Mutual Fund Performance, 1965-1984. The Quarterly Journal of Economics, 104(1), 1-23. http://dx.doi. org/10.1108/ilds.2002.12230dab.004. 
Jagannathan, R., \& Korajczyk, R.A. (1986). Assessing the Market Timing Performance of Managed Portfolios. The Journal of Business, 59(2), 217-235. http://dx.doi. org/10.1086/296326.

Jensen, M.C. (1968). The Performance of Mutual Funds in the Period 1945-1964. The Journal of Finance, 23(2), 389-416. http://dx.doi.org/10.1111/j.1540-6261.1968. tb00815.x.

Jiang, W. (2003). A nonparametric test of market timing. Journal of Empirical Finance, 10(4), 399-425. http://dx.doi.org/10.1016/S0927-5398(02)00065-8.

Kon, S.J., \& Jen, F.C. (1979). The Investment Performance of Mutual Funds: An Empirical Investigation of Timing, Selectivity, and Market Efficiency. The Journal of Business, 52(2), 263-289.

Lee, C.-F., \& Rahman, S. (1990). Market Timing, Selectivity, and Mutual Fund Performance: An Empirical Investigation. The Journal of Business, 63(2), 261-278. http:// dx.doi.org/10.1086/296505.

Mohanti, D., \& Priyan, P.K. (2018). Style-exposure analysis of large-cap equity mutual funds in India. IIMB Management Review, 30, 219-228. http://dx.doi.org/10.1016/j. iimb.2018.01.010.

Pesaran, M.H., \& Timmermann, A. (1995). Predictability of Stock Returns: Robustness and Economic Significance. Journal of Finance, 50(4), 1201-1228. http://dx.doi. org/10.2307/2329349.

Sehgal, S., \& Babbar, S. (2017). Evaluating alternative performance benchmarks for Indian mutual fund industry. Journal of Advances in Management Research, 14(2), 222250. http://dx.doi.org/10.1108/JAMR-04-2016-0028.

Sehgal, S., \& Jhanwar, M. (2008). On Stock Selection Skills and Market Timing Abilities of Mutual Fund Managers in India. International Research Journal of Finance and Economics, 15(15), 307-317.

Sharpe, W.F. (1966). Mutual Fund Performance. The Journal of Business, 39(1), 119-138. http://dx.doi.org/10.1086/294846.

Treynor, J.L. (1965). How to rate management of investment funds. Harvard Business Review, 43, 63-75. http://dx.doi.org/10.1002/9781119196679.ch10.

Treynor, J. L., \& Mazuy, K. (1966). Can Mutual Funds Outguess the Market? Harvard Business Review, 4, 131-136.

Tripathy, N.P. (2005). An empirical evaluation of market timing abilities of Indian fund managers on equity linked savings scheme. Delhi Business Review, 6(2), 19-27.

Tripathy, N.P. (2006). Market Timing Abilities and Mutual Fund Performance-An Empirical Investigation into Equity Linked Saving Schemes. Vilakshan, XIMB Journal of Management, 127-138. 